\author{
V International Forum on Teacher Education
}

\title{
Bilingual Training of the Future Teacher in the Multicultural Educational Space
}

\author{
Elmira Sh. Salimzyanova*
}

Kazan Federal University, 420008, Kazan (Russia), 18 Kremlyovskaya street

\begin{abstract}
The article is devoted to the disclosure of the essence and content of the concepts of 'multicultural educational space', 'multicultural competence of the teacher' and 'bilingual training of the future teacher'. The relevance of the present issue is caused by the intensive development of integration processes in the world community, the formation of a single economic, informational, cultural, educational space, a multiple increase in migration flows, an increase in the level of interregional and international cooperation, the expansion of contacts of different cultures and languages. The aim of the article is to reveal the content and meaning of bilingual training of the future teacher in the multicultural educational space, as well as the criteria of its formation among graduates from the pedagogical direction of training. The leading method for studying this problem is modeling, which allows considering this problem as a process of purposeful and conscious mastering by future teachers of bilingual training in a multicultural educational space. The obtained results and conclusions open up new opportunities for further research of the conditions and directions of bilingual training of future teachers in the multicultural educational space.
\end{abstract}

Keywords: bilingual training; bilingual education; multicultural education; multicultural competence of the teacher.

(C) 2019 Elmira Sh. Salimzyanova

This is an open access article distributed under the terms of the Creative Commons Attribution License (CC BY 4.0), which permits unrestricted use, distribution, and reproduction in any medium, provided the original author and source are credited.

Published by Kazan federal university and peer-reviewed under responsibility of IFTE-2019 (V International Forum on Teacher Education) 


\section{Introduction}

In the conditions of transformation of modern school into a multicultural educational space, the problem of multicultural competence of a teacher is extremely relevant, and therefore a mandatory element of modern pedagogical education is the training of a competent specialist who is able to guarantee the formation of a base of universal, national and cultural values among students. Polycultural education is the process by which an individual acquires a system of knowledge and skills: general cultural, linguistic, professional, etc., aimed at ensuring readiness for a comfortable existence in the dynamic conditions of a multicultural society.

In our opinion, in modern conditions, the most complete tasks of personality formation in a multicultural education are education on a bilingual basis as mastering by future teachers of subject knowledge in a certain field based on the use of two languages, which act simultaneously as a means of educational activity. Questions of bilingual education for pedagogical specialties are described in detail in many scientific works, while the very concept of "bilingualism" is considered from various points of view. For example, in his study Timofeev (2015) provides a bilingual model of professional training of future teachers of a foreign language. In her work Sorochkina (2000) proposes an integrated model of bilingual education in the modern Russian school, which involves the synthesis of various approaches and concepts of bilingual education, and also aims to achieve basic bilingual competence. Despite this, the main problem of the implementation of the bilingual approach in education still remains unresolved, since when teaching a foreign language both at school and at the university, the core orientation of education is not taken into account. Even in the case of training teachers in dual specialties, one of which is a foreign language, the ability to integrate the two specialties is not fully realized (Salekhova, 2008). This problem persists to this day, despite the large number of works devoted to various features of bilingual education.

\section{Purpose and objectives of the study}

The purpose of this study is to generalize the scientific-theoretical and technological bases of the formation of bilingual competence of future teachers, necessary for the communicative development in a dialogue of cultures and multilingualism. Professional training of future teachers for communicative and speech-development of bilingual personality is realized through a special systematically organized and differentiated technological complex of training, integrating traditional and innovative pedagogical technologies through communication.

The object of the research is the theory and practice of the formation of multicultural competence among students, bilingual readiness for pedagogical activity as the basis of their speech-thinking culture. The subject of the research is the pedagogical conditions for the effective formation of the bilingual verbal culture of the future specialist as the most important component of teacher training.

\section{Literature review}

Davydova (2013) revealed, substantiated and approved the forms, methods and means of designing and applying electronic bilingual dictionaries in pedagogical disciplines. She identified and substantiated the essence of the concepts "bilingual terminological dictionary", "electronic bilingual dictionary on pedagogical discipline", "bilingual readiness for pedagogical activity" based on the analysis of pedagogical, linguistic and lexicographical theory and practice. The scientist has developed a model for designing electronic bilingual dictionaries in pedagogical disciplines based on the study of their didactic possibilities. She defined the specifics of designing electronic bilingual dictionaries by pedagogical 
disciplines. Davydova (2013) defined the structure of the electronic bilingual dictionary on pedagogical discipline, the typology of the dictionary entries included in it, and their structure depending on their type.

Gukalenko (2005) developed the principles of migrant pedagogy. She believes that a special multicultural environment should be created in the modern school with migrant children. Scientist believes that the school curriculum should include systematic teaching of the student's native language, as well as activities related to the introduction of its national culture; the school should ensure true bilingualism and biculturalism, through which equal development of languages and harmony of both cultures is achieved.

Gubanikhina (2015) reflected the competence of a teacher in a multicultural society. The concept of multicultural competence of a teacher is introduced as a significant integral characteristic in a modern educational environment. According to Gubanikhina (2015), in modern conditions, the multicultural competence of a teacher is not a separate complex of characteristics, but an integral part of general pedagogical competence. Conducted survey showed that at the initial stage of professional pedagogical education, most students are not yet ready to work in a multicultural team, but seek to gain the knowledge necessary for this. The educational environment is constantly being improved: new principles and approaches are being developed to create a multicultural society based on ethnic tolerance, the ability to adapt to the ethnic educational environment, tolerance for individual differences of other people, cultural interaction with representatives of other ethnic groups, mutual understanding and mutual assistance. Great responsibility falls precisely on the shoulders of the teacher, so multicultural competence is so valued in our day.

In the study of Khupsarokova and Khakunova (2011) the concept of multicultural competence is analyzed. The authors define multicultural competence of the teacher as a socially and professionally significant personal quality. The structure and the content of the teacher's multicultural competence are characterized and criteria for its formation are given.

According to the point of view of Russian scientists, the new socio-economic and political situations require the implementation of a language policy in the field of language education aimed at satisfying both public and personal needs. With the implementation of the new language policy, the creation of a flexible system of languages and the conditions for their study, as well as a variation of forms and means of teaching, reflects the current state of the theory and practice of teaching a foreign language. In this regard, the foreign language in the system of continuing professional education has acquired a broad scale. The purpose of this study is to systematize the experience of creating a model of life-long foreignlanguage education in the system of continuing professional education, describing it through the prism of theoretical and methodological approaches. The model needs to be characterized, firstly, to comprehend what was done and outline the next steps in improving the system, and secondly, it will be useful for managers working in continuing professional education. This study can be beneficial for the learners, who prefer to know from which approaches educational programs and courses are built, which they still choose or have already chosen for training (Nurutdinova et al., 2018).

Salekhova (2008) comprehensively studied the theoretical and pedagogical heritage of bilingual education by means of native and foreign languages in Russia from the middle of the 20th century to the beginning of the 21st century. On this basis, she developed a subject-oriented model of bilingual education in mathematics and experimentally proved the didactic possibilities of its implementation in a pedagogical university.

Salimzyanova's work (2018) is aimed at finding the main ways of achieving mutual understanding of the participants of intercultural business communication, productive implementation of 
this communication in the light of modern requirements. The author considers ways to overcome the language barrier by the example of communicative practice in English as the language of international communication. It also focuses on the conditions for successful communication in the multicultural space, examines and presents the most effective strategies for achieving mutual understanding between business partners.

Sorochkina (2000) developed and theoretically substantiated an integrative model of bilingual education in the national school, synthesizing various didactic goals and aimed at the formation of basic bilingual competence. She gave a generalized description of bilingual education models existing in domestic and foreign practice, developed a typology of bilingual education models by the criterion of didactic goal-setting, revealed the essential characteristics of an integrative bilingual education model in a national school. The scientist also substantiated the concept of basic bilingual competence as an educational result, studied the influence of the developed bilingual education model on such personality characteristics as general tolerance and tolerance to national and cultural differences, ability to constructively resolve conflicts.

The purpose of the study Timofeev (2005) is the theoretical justification, construction and experimental testing of the bilingual model of professional training of a future teacher of a foreign language, implemented in an interdisciplinary process of formation of readiness for professional activities based on bilingual LR-competence of mixed type. He analyzed the psycholinguistic, psychological and pedagogical, didactic and methodological aspects of the formation of the mechanism of bilingualism, which form the design basis for professional training of a foreign language teacher. He identified the essential characteristics, structural components and the criteria for the formation of students' readiness for professional activities based on mixed-type bilingual LR-competence, developed the design characteristics of the process of forming this type of readiness, its organizational, managerial and didactic and methodological support within the bilingual model of training the future teacher foreign language. The scientist has identified and experimentally verified the pedagogical conditions for effectively shaping the readiness of future foreign language teachers for professional activities based on mixed-type bilingual LRcompetence.

Zhukova (2009) identified the problems of cross-cultural communication of students and the possibilities of its development in a socio-cultural environment of the university. She analyzed the conceptual foundations of cross-cultural communication, identified the features of the student sociocultural environment as the basis for the development of cross-cultural communication, revealed main components of cross-cultural competence. She also implemented diagnostics of cross-cultural competence of students, has developed a technological model for the formation of development conditions crosscultural communication of students.

\section{Methodology}

To solve the set tasks and check the initial positions, a complex of complementary methods was used: analysis, systematization, generalization, comparison of philosophical, social, psychological, pedagogical and methodical literature; analysis of the features of a multicultural educational institution and approaches to the processes of education and training in it; studying the experience of training future teachers; modeling; pedagogical situations and games; survey methods (interviews, questioning, interviewing, blitz polls, testing); pedagogical experiment, as well as methods of statistical processing of quantitative research results. The experimental base of the research was Kazan (Volga Region) Federal 
University. The study of the problem was carried out in three stages: at the first stage, a theoretical analysis of the existing methodological approaches in philosophical, psychological and pedagogical scientific literature, dissertation works on the problem, as well as the theory and methodology of pedagogical research was carried out; highlighted the problem, the purpose and methods of research, made a plan of experimental research.

\section{Results}

In this study, we considered the preparation for the pedagogical activity of the teacher as the quality of the personality, ensuring its optimal activity in organizing the process of training and education, self-development and self-government of students as subjects in their joint activities. According to another interpretation, preparation for pedagogical activity is a set of professionally determined requirements for the teacher: this set of requirements includes didactic, constructive, perceptual, expressive, communicative and organizational skills.

In the context of bilingual education, there is a simultaneous assimilation of the theoretical component of the educational material, as well as the development of communication skills. This fact allows us to single out bilingual training as an independent component in the system of pedagogical activity. Since there is no such term as "bilingual training" in general pedagogy and in pedagogy of professional education, let us make an attempt to reveal the general pedagogical meaning of the concept "bilingual preparation for pedagogical activity". Speaking about the bilingual preparation of the teacher, we mean not only the knowledge of pedagogical terms, but also the ability to translate them from a foreign language into one's native language, the ability to use them in professional speech and read original pedagogical literature. Therefore, we believe that the basis of correct professional speech and reading skills of the original pedagogical literature is knowledge of the relevant terminology in a foreign language. At the same time, the effectiveness of pedagogical discourse, in accordance with its definition, is largely due to the personal orientation of the individual, his desire and motivation. This presentation allows us to consider the bilingual training of a teacher not only as the availability of theoretical knowledge and practical skills in the use of foreign language pedagogical terms, but also as a combination of the necessary psychological and personal personality traits.

Thus, bilingual preparation for pedagogical activity is a set of general pedagogical, interdisciplinary, intercultural and special (methodical and subject) knowledge, skills, and professionally significant personal qualities that ensure successful practical activity of a teacher in intercultural bilingual communication. As shown above, it can also be structurally represented by theoretical, operational, and motivational components. Bilingual preparation is one of the components of teacher preparation for teaching activities, being one of the essential factors for successful implementation of teaching activities in modern multicultural conditions.

Speaking about polycultural education, it is also necessary to consider the content of the concept "multicultural competence", since it is this category that determines the teacher's readiness for professional activity. From the point of view of Gubanikhina (2015), the term "multicultural competence" is an integral characteristic of a teacher, which is a system of multicultural knowledge, skills, abilities, values, interests, multicultural qualities, experience necessary for life and activities in a multicultural society, for interaction with various cultures (people of different races, nationalities, social groups, beliefs). According to Zhukova (2009), the criteria for multicultural competence are the following aspects: multicultural awareness; cultural identity; regulatory identity. 
Polycultural competence of teachers is the result of their multicultural education, manifested in their general ability and readiness for activity, based on knowledge and experience, which are acquired in the process of learning and socialization and are focused on independent and successful participation in professional activities. It is obvious that bilingual preparation for pedagogical activity is the dominant for the successful formation of the multicultural competence of the future teacher. And to assess the degree of its development among graduates of the pedagogical direction of training, we have allocated 4 levels (Davydov, 2013):

1. The reproductive level at which students demonstrate a rather low level of knowledge of the basic concepts of the subject area in a foreign language is not conscious of itself as a subject of pedagogical activity. Trainees of this level lack readiness for bilingual pedagogical activity, motivation and focus on it.

2. Productive level. Students have general theoretical and methodological knowledge in the field of bilingual education, but at the same time they have difficulty translating theoretical concepts into specific technological and methodological developments, as well as using the pedagogical terminology in a foreign language for each case. The trainees also have difficulties in evaluating the process and the result of their own actions, they are not strongly motivated to carry out bilingual pedagogical activity, they lack purposeful expression of personality.

3. For the heuristic level, the level of knowledge of general and subject terminology in a foreign language and readiness for teaching activity that is sufficient for performing professional tasks is characteristic. At the same time, at this level, there is an uneven development of all components of bilingual preparation for pedagogical activity, but there is a tendency for their stability, consolidation and strengthening. The actions of the students are conscious, but limited to the framework of the studied. The pedagogical orientation of the personality is clearly expressed, the necessary psychological qualities are present for the implementation of successful pedagogical activity in the context of bilingual education.

4. The creative level fixes the formation of all components of bilingual pedagogical readiness in their unity and interaction, including knowledge, skills, needs, motives, attitudes and state of the individual. Students strive to avoid stereotypes, monotonous actions, constantly look for new theoretical and practical solutions, are able to independently evaluate and correct their own practical activities, and strive to apply the studied pedagogical terms in a foreign language when conducting classes. The readiness of this level can be characterized as formed.

Experimental work in comparative pedagogical experiments, which are divided into three stages:

1) stating - determining the initial level of multicultural competence of future teachers, based on the development of abilities, qualities, skills and abilities, experience of interacting with people from other cultures, analyzing existing knowledge and ideas about multiculturalism, value orientations, motivation of educational and cognitive activity and social cultural communication;

2) formative - the development and inclusion in the curriculum of future teachers of disciplines of a multicultural nature; implementation of the identified pedagogical conditions in the educational process;

3) control - identifying the level of multicultural competence achieved by respondents, using a comparative analysis of the level dynamics; analysis and interpretation of the results.

A comparative analysis of the data obtained as a result of the experiment at the ascertaining and formative stages showed a positive dynamics in the formation of multicultural competence students - future teachers. Thus, the implementation of the author's model of pedagogical conditions for the formation of multicultural competence in the educational process of future teachers' bilingual training for pedagogical 
activity in the multicultural educational space is effective.

\section{Discussions}

Questions of bilingual education for pedagogical specialties are described in detail in many scientific works, while the very concept of "bilingualism" is considered from various points of view. For instance, the study of Timofeev (2005) provides a bilingual model of professional training of future teachers of a foreign language. Sorochkina (2000) proposes an integral model of bilingual education in the modern Russian school, which involves the synthesis of various approaches and concepts of bilingual education, and also aims to achieve basic bilingual competence.

Nevertheless, the main problem of the implementation of the bilingual approach in education still remains unresolved, since when teaching a foreign language both at school and at the university, the core orientation of education is not taken into account. Even in the case of training teachers in dual specialties, one of which is a foreign language, the ability to integrate the two specialties is not fully realized (Salekhova, 2008). This problem persists even now, despite the large number of works devoted to various features of bilingual education: general theoretical foundations, linguistic, psychological, sociological aspects, etc.

The fact is that the problem of bilingual education was studied in parts, outside the systems approach. As a result, there are many disparate facts, comparing which you can get a fundamentally new learning model that would contribute not only to the development of students' language competence, but also to the formation of the general readiness of the teacher for teaching activities, including bilingual knowledge and skills.

Speaking about polycultural education, it is also necessary to consider the content of the concept "multicultural competence", since it is this category that determines the teacher's readiness for professional activity. Gubanikhina (2015), under the term "multicultural competence", means the integral characteristic of a teacher, which is a system of multicultural knowledge, skills, abilities, values, interests, multicultural qualities, experience necessary for life and activities in a multicultural society, for interaction with various cultures (representatives of different races, nationalities, social groups, beliefs).

According to Zhukova (2009), the criteria for multicultural competence are: multicultural awareness (a set of knowledge of cultural artifacts, patterns of behavior, understanding of the need and adherence to scenarios of native or other culture or subculture behavior); cultural identity (the result of cultural identification, i.e. correlation and identification with cultural norms and patterns of behavior); normative identity (knowledge, understanding and acceptance of social norms).

Khupsarokova and Khakunova (2011) highlight the following criteria for a teacher's multicultural competence: 1) awareness of the multicultural characteristics of the team, including the student team, and respect for them; 2) the ability to act in accordance with the cultural characteristics of subjects of pedagogical activity, while maintaining their own cultural identity; 3) the ability to organize effective cultural interaction. The structural components of the multicultural competence of teachers are: cognitive; motivational and value; activity. The cognitive component assumes the formation of a system of multicultural knowledge, serving as an indicative basis for the activity of a person in a multicultural society. The motivational and value component is an established system of motivational and value formations: motives, values, interests, needs, and multicultural qualities that regulate the daily life and activities of the individual in a multicultural society. The activity component ensures the formation of multicultural skills and abilities, compliance with social norms and rules of behavior in a multicultural 
society, the experience of positive interaction with people of different cultures, as well as the ability to organize the pedagogical process as a dialogue of carriers of different cultures in time and space.

Numerous scientific works of Russian researchers (Gubanikhina, 2015; Khupsarokova, 2011; etc.) confirm the fact that effective formation of multicultural competence in future teachers is possible only if the patterns of development of the value-oriented, motivational and activity-behavioral spheres of a person are taken into account, staged organization of the process of assimilation of social and professional experience of multicultural interaction, as well as relying on the main tenets of the theory of multicultural education, role theory of personality and competence-based approach to training.

\section{Conclusion}

Assessment of the level of bilingual training for students' pedagogical activities is carried out in accordance with the specified criteria by monitoring students' theoretical and practical readiness for pedagogical activities, the level of their language competence in a given subject area, as well as their personal focus on pedagogical activities. Numerous scientific works of domestic researchers confirm the fact that effective formation of multicultural competence among future teachers is possible only if we take into account the laws governing the development of value-orientation, motivational and activity-behavioral spheres of a person, the staged organization of the process of assimilating social and professional experience of multicultural interaction, as well as supporting on the main provisions of the theory of multicultural education, role-based theory of personality and competence approach to professional training.

In modern conditions, the multicultural competence of a teacher is not a separate set of characteristics, but an integral part of the general pedagogical culture. The foundations of human multicultural competence begin to be laid in the first years of a child's life and are based on universal human basic values, in particular, on the formation of a feeling of patriotism. However, the teacher's multicultural competence is laid at the stage of vocational education, in the period of obtaining secondary or higher vocational education. Only in this case, the teacher will become involved in the problems of society: being a carrier of tolerant consciousness, he will be able to convey the range of his attitudes, beliefs, attitudes to his students and, thereby, he is able to humanize society.

\section{References}

Davydova, A. A. (2013). Designing electronic bilingual dictionaries in pedagogical disciplines. PhD Thesis. Smolensk.

Gubanikhina, E. V. (2015). On the issue of multicultural competence of a teacher. Molodoi uchenyiYoung scientist, (4), 556-559.

Gukalenko, O. V. (2005). Multicultural education: theory and practice. Moscow: Publishing Service.

Khupsarokova, A. M., Khakunova F. P. (2011) The subject-specific components of the multicultural competence of the teacher. Vestnik Adygejskogo gosudarstvennogo universiteta - Bulletin of Adyghe State University, 1(72), 47-52.

Nurutdinova, A. R., Zakieva, Z. R., Ismagilova, L. R., Nurova, L. R., Nelyubina, E. A., Salimzyanova, E. Sh., Konova, A. I. (2018). Skill Conversion: The Life-Long Foreign-language Education In The System of Continuing Professional Education. Modern journal of language teaching methods, 8(11), 566-579.

Salekhova, L. L. (2008). Didactic model of bilingual education in mathematics in the higher pedagogical school. Doctoral Dissertation. Kazan. 
Salimzyanova, E. Sh. (2018). Preparation of future specialists for intercultural communication in professional discourse. Obrazovanie - Education, 4(87), 61-66.

Sorochkina, N. E. (2000). Integral model of bilingual education in the modern Russian school. PhD Thesis. Velikiy Novgorod.

Timofeev, A. V. (2005). Bilingual model of professional training of a future teacher of a foreign language. Sochi: RIO SGUTiKD.

Zhukova, T. V. (2009). Problems of cross-cultural communication of students. Moscow, Moskovskii gosudarstvennyi universitet. 